\title{
Immigrant's Way of Creating a Piece of Home in Abroad: Foodways, Religion, Gender and Norms
}

\author{
Muhammad Ilias \\ Assistant Professor, Department of Sociology, Begum Rokeya University, Rangpur, Bangladesh
}

\begin{abstract}
Food is who we are in a deepest sense, and not because it is transformed into blood and bone. Our personal gastronomic traditions- what we eat, the foods, and foodways we associate with the rituals of childhood, marriage and parenthood, moments around the table, celebrations- are critical component of our identities. To recall them in desperate circumstances is to reinforce a sense of self and to assist us in our struggle to preserve it."I
\end{abstract}

This above statement is the reflection of the situation the author had went through. It also explains the psychological ways dealing with the struggles in the concentration camp of Terezin. The tiny hope they had about the future. Seeking of satisfaction and happiness in that ghetto life through deepest involvement into something that serves the need to mind, that connects people with their most familiar circumstances, which are more or less a symbol of one's self and identity. There are many aspects highlighted in the statement. It said that food is not merely what we are eating and hence our body is transforming into something good. Rather it's beyond that. Food is, almost similar to the definition of culture, what we are.

\section{INTRODUCTION}

$\mathrm{C}$ ulture is something we build in one environment, but it al so takes us into a new situation of life or into new living s paces. The cuisine and food culture are no different from other cultural expressions in that case. It can be re-created at a new location or in a new situation and environment as a potable value. Sources of this are how we transfer our food culture through life in our childhood, from the time we leave home, to the situation when we form a new family, and to the old age. As people migrate, they come into contact with cultures that are new and different. The alienation from the usual dietary practices and the challenge of finding new foods and eating ways in the new environment (host country / region) becomes central to the integration process. However, this assimilation does not by any means overshadow the complexity of multiple identities within each individual and the whole family. Such ideologies become more complex as the second and third generations go on to become migrants themselves, and it is the interaction between these cultures that characterizes their eating habits. In the social life of the diaspora, food plays an important role: it can create a sense of continued belonging and reiterate affiliations with ' home. ' Following discussions on nutrition, gender, ethnicity and commensality, food preferences have been shown to promote the creation of distinct migrant subjectivities and community identities through both inclusion - reaffirming migrant relationships -

${ }^{1}$ In Memory's Kitchen: A Legacy from the Women of Terezin (Page 26) and exclusion - in that others in the host region do not share migrant tastes. Bangladeshi immigrants also use to go through various adaptation process in order to maintain their identity and culture. Their original foodways and culture related to food use to reorganize itself.

\section{Objectives}

The objective of the research paper is to find out the process of adaptation with the foodways by the immigrant people in the host country. While understanding the process I will try to focus on:

1. The culinary habit and cuisine of the home country to compare how much it is different from the host country and it will also give us an idea of what is missing.

2. I would also try to see the nature of food supermarket in the home country to get an insight.

3. The paper will also look forward to see if any literature shows that people tend to change their habits of cooking or eating with special reference to gender based practices or religious integration based practices.

\section{METHOD AND FOCUS OF THE PAPER}

The main intend of the paper is to gather background information and thus generate idea about few issues related to the topic of interest. Hence, the method being adopted is analyzing available literatures and materials. There are many key concepts which my paper will try to focus on. These are migration, food culture of home country, nature of food market in the home country, religion as dynamic in the foodways in home country, nature of food market and food culture in USA, food as a symbolic way to carry the identity, negotiating and adapting to the food culture of USA, gender and the adaptation process, religion and the adaptation process. All these above mentioned measures will lead to the better understanding of the central concept of immigrant's adaptation process with new food.

\section{Traditional Food Culture in Bangladesh}

Shaheda Yesmin in an article, published in a daily newspaper, has precisely described the traditional Bangladeshi food and she said,

"The Bangladeshi culinary tapestry is steeped in tradition and famous for its distinctive taste, be it savoury or sweet. Bhat, 
meaning boiled rice, is the staple. The old saying 'MacheybhateyBangali' meant that rice and fish form the culinary base of Bangladeshi cuisine, and 'Golabhoradhanarpukurbhoramach' implied the abundance of both in Bengal. While the sayings may have been true, they miss the fact that a wide variety of leafy vegetable, or shak, which is also available in plenty, forms an integral and diverse part of the Bangladeshi rural and urban cuisine, as do lentils and a variety of gourds. It is also true that meat preparation of mutton, beef, duck and chicken, preferably free-range chicken, are a common and essential part of Bangladeshi cuisine. Then there is the meat centric sublime Mughal cuisine that adds to the diversity. "2

Despite being young in age, Bangladesh is a country rooted in a culture and tradition that is millennium old. Like all other cultures, the culture of Bangladesh is the result of a mixture of geography and religion. In everything from food to media to marital rituals, the influence of geography and religion can be seen. Bangladesh is a predominantly Muslim country that has an influence on its society in all respects. Bengali cuisine, for example, will never feature pork dishes, nor will any dish ever see wine as an ingredient.Spice is one of the most common ingredients in Bengali cuisine. Nearly all major Bengaliinfluenced dishes contain some type of flavor spice. Spice's focus on Bengali cuisine is representative of the region that is renowned for its spices. While being a staple of Bengali cuisine, spices are not the most important part of the Bengali diet.

Rice is the staple food of Bangladeshi people. Traditionally Bangladeshis eat rice as Bhat (boiled rice) as their staple food and major intake. About 70 percent of what they eat is based on rice, which is their main source of carbohydrate. ${ }^{3}$ Rice is also used as polao (sunny rice cooked with spices), biriani (sunny rice cooked with chicken or mouth cooked with spices \& condiments), chira (flattened rice), muri (puffed rice), hotchpotch and other preparations. According to Mahmud,

"For last few decades wheat has become part of the Bengali menu but still not common specially in the rural area. Few decades ago when there was scarcity of rice, wheat was considered as poor peoples' food. People ate wheat only when they were fallen into scarcity of rice. But, now the situation is being changed. Health conscious people take rooti or chapati(wheat-based food items) at least once in a day on a regular basis specially in the urban area." 4

But wheat is not yet common in the rural area. There were also other carbohydrate sources a few decades ago, such as cown (one type of food grain), barley, etc., which are now

\footnotetext{
${ }^{2}$ https://www.thedailystar.net/lifestyle/spotlight/bangladesh-cuisine-part-idelectable-and-diverse-1325551 retrieved on 10/25/2019

${ }^{3} \mathrm{http} / / /$ en.wikipedia.org/wiki/Bangladeshi_cuisine/

${ }^{4}$ Mahmud, A. (n.d.). Traditional Food Culture \&amp; Food Security in Bangladesh. Retrieved from

https://www.academia.edu/32445513/Traditional_Food_Culture_and_Food_S ecurity_in_Bangladesh
}

almost disappeared mainly due to rice monoculture. Bhat is eaten after mixing with various types of curry, bhaji (fry), bharta (mash), etc., unlike other foods. Bhaji and Bharta are generally made up of countless vegetable and fish types. The curry is prepared separately or mixed or combined with fish or meat with different kinds of vegetables. Different types of dal (soup made from various pulses such as lentil, mung bean, khesari, gram, pea etc.) are also mixed with bhat. There are also various types of ghonto that are commonly eaten with bhat (mixing herbs, pulses, and even big fish heads). Different types of ghonto are also commonly eaten with bhat (mixing herbs, pulses, and even big heads of fish).

ShorsheIlish has been an important part of Bengali cuisine, a dish of smoked ilish with mustard seed paste. Depending on the texture, length, fat content and bones, there are various ways to cook fish.

"Bangladesh has more than forty types of mostly freshwater fish are common, including carp varieties like rui (rohu), koi (climbing perch), the wriggling catfish family - tangra, magur, shingi, pabda (the pink-bellied Indian butter fish), katla, ilish (ilish), as well as shuţki (small dried sea fish). Chingri (prawn) is a particular favourite and comes in many varieties - kucho (tiny shrimp), bagda (tiger prawns) or galda (Scampi). All of these are fresh water fishes. "5

In the preparation of Bengali dishes, different spices and condiments are used. Cumin powder, cumin powder, cumin, red chilli powder, turmeric powder, ' panchphoran ' and coriander powder are popular among them. Various types of sweets are an integral part of Bangladeshi people's food culture. Pithas (homemade cake) are an integral part of Bangladesh's traditional food culture. But what is popular in the Western world and in their food culture is not like the conventional cake or pie. In Bangladesh, sarbat, prepared with water, sugar and lemon, is a common drink. Green coconut water is also served in the countryside as fresh ready-made drinks. Often served as beverages is Borhani, but not other than some large ceremonies such as marriage. Lassi is a refreshing drink of yogurt that is also served mostly by rich people. Fruit is not traditionally regarded as food in the country. Therefore, no fruit is eaten in the country's rural area connected with daily meals. Traditional fruits are now rarely available because of the aggression of a few expensive exotic fruits such as apple, orange, grape, etc.

\section{Regional Diversity of Bangladeshi Cuisine}

While Bangladesh is made up of eight administrative divisions and sixty-four districts, this does not necessarily define the culinary diversity; it is widespread across the region. The differences are also influenced by the palate, preparation and tradition of different regions.

\footnotetext{
${ }^{5}$ Mahmud, A. (n.d.). Traditional Food Culture \&amp; Food Security in Bangladesh. Retrieved from https://www.academia.edu/32445513/Traditional_Food_Culture_and_Food_S ecurity_in_Bangladesh
} 
ShahedaYesmin ${ }^{6}$ addressed of these regional differences in food culture and preferences. It is important to understand the cuisine type of people from various parts of Bangladesh because, thus I would be able to know the original food habit of immigrants based on their actual residence in Bangladesh.

For example, Dhaka cuisine is heavily influenced by Mughal traditions that go back to Mughals ' presence in this area. Also known for bakorkhani is Dhaka, a thick and spicy flat bread originating in old Dhaka. Chittagong, the port city of Bangladesh, situated along Bengal's picturesque and strong Bay, offers its own food brand. Her quintessential goshtmezbani dish, or beef curry eaten by visitors, is the best known. Chittagong is known for its variety of shutkis (dried fish), fresh fried rupchanda (pomfret) and fresh loitta fried fish, which is a local delicacy. Sylhet, located in the country's north-eastern region, has its own delicacies and is renowned for its lush green tea plantations. The south west area is supplying the best of crustaceans such as lobsters, prawns, shrimps and crabs. The people of this region use coconut milk and other coconut by-products for their cuisine due to the abundance of coconut trees. The north-west area provides the country's bulk of vegetables. This is why this region's cuisine has a strong presence of vegetables in various forms. Potato is a major product and comes in different varieties, particularly popular with red potatoes.

\section{Food and Supermarket}

Bangladesh's retail trade was in the hands of thousands of unorganized small traders in urban wet markets and grocery stores a decade ago. In basic sanitation facilities, these shops are congested and seriously lacking.

"As of 2013, an estimated 30 companies operate about 200 supermarket-format retail outlets in Bangladesh. These chains are gradually gaining popularity among the urban population in major Bangladeshi cities. However, socioeconomic changes (e.g., rising per-capita incomes, increasing urbanization, and a growing number of women working outside the home) necessary for consumers to adopt supermarkets are proceeding more slowly in Bangladesh than in neighboring India and Sri Lanka. "7

Bangladesh has a variety of supermarket environments, some with a complete supermarket layout (Khulshi Mart, Shwapno, Well-Mart and Agora) and others with a smaller format.The retail firms have attempted a massive expansion to attract shoppers who still rely on wet markets to buy their daily necessities. Most small and large supermarkets have made their debuts in the past decade, targeting customers of the middle and upper middle class. However, most customers in Bangladesh will not change their shopping habits in the near future.

${ }^{6}$ https://www.thedailystar.net/lifestyle/spotlight/bangladesh-cuisine-part-idelectable-and-diverse-1325551 retrieved on 10/25/2019

${ }^{7}$ Khan, md makshud A. (n.d.). The Food Retail Sector in Bangladesh. Retrieved from

https://www.academia.edu/8014343/The_Food_Retail_Sector_in_Bangladesh

\section{Food and Religion}

Through food patterns, people connect to their cultural or ethnic group."Food is often used as a means of retaining their cultural identity. People from different cultural backgrounds eat different foods. The areas in which families live and where their ancestors originated influence food like and dislikes. These food preferences result in patterns of food choices within a cultural or regional group". ${ }^{8}$ Religious beliefs and myths have a tremendous influence on the country's traditional food culture. Only Muslim and Hindu religions were considered here because in the study area, the peoples of other religions are not so much available. Mythologically, however, both Hindus and Muslims regard food as God's gift to humans. There is a belief among Muslims that if Allah does not give food (Rizik) to him or her, no one can take food. On the other hand, according to Hindus myth Food is like God Laxmi's gift, too.

In the fields of anthropology, sociology and cultural studies, food has been widely studied. The question that comes to mind when someone talks about or considers food is where it comes from and how does it taste, and how does it contribute to culture? People usually turn to the cultural and religious background to provide the answers to these questions. The word culture refers to the set of values, traditions, vocabulary, practices, behaviors, lifestyles, attitudes, beliefs, tradition, laws, and customs that at a specific point in time define a particular group of people. Some think of culture as beliefs, signs, meanings, and points of view that differ from each other in modernized cultures; they are not material objects and other observable aspects of human societies. The sense of signs, objects, and actions is usually interpreted by people within a society in the same or similar ways. Culture is formed, developed, transmitted and learned through interaction, and culture creates, forms and transmits communication activities.

There are certain foods that are restricted in the religion of Hindu and Islam. The Hindus never eat beef because they consider cow as one of their gods. But they're drinking cow's milk. Also, in most cases, the Hindus do not eat onion and garlic, especially during the puja period (Hindus prayer). Fish and meat are also prohibited in most cases during puja period. The Muslims, on the other hand, never eat pig meat because it is prohibited in Islam religion. In Islam, wines or such hard drinks are also banned. In both Islam and Hindu religion, there are some religious practices such as holy fasting (Ruja for Islam \&Upabash in Hindu) when food is prohibited. Most of Bangladesh's festivals are religious festivals that both Muslims and Hidus have observed.

\section{Gender and Food}

In Bangladesh's traditional food culture, there are many discriminatory elements. Woman is one of the worst victims

\footnotetext{
${ }^{8}$ Sibal, Vatika. (2018). FOOD: IDENTITY OF CULTURE AND RELIGION.
} JULY-AUG, 2018 Volume 6,. 10908-10915). 
of this kind of discrimination. Discrimination starts for a woman from the very childhood as mentioned in Annaprashan's description.

"In Annaprashan of Hidus the girl child is given bhat for the first time later than a boy child. Although Annaprashan is a Hidu ritual but such discrimination is observed in case of all religious sections of people in the country. If a woman takes more food she is treated as a bad woman in the family and the society. So, irrespective of religion the girls are taught to take less food compared to the male counterpart from the very childhood." 9

The women have to wait at home with food until the male members have returned home even in late. The males take the best portion of the foods in a family first. The women eat whatever food the male family members have left after they have taken. The women often do not get enough food to eat in the poor families where food is not abundant. As a result, women often experience malnutrition and various types of health hazards. Bengali woman traditionally goes after marriage to the husband's house. According to the marriage contract, the husband is responsible for providing his wife with meat. Therefore, the male remains dominant over the female at all times. Also, Widows did not use "heating" foods like onions and garlic, but ginger was permitted-this found a central place in both vegetarian and non-vegetarian Bengali curries.

Domestic cooking and cooking for non-domestic purposes are differently integrated with the men and women living in Bangladesh. These responsibilities or assignments also vary from rural to urban areas. Villages are characterized by the prevalence of agriculture based economy, low income rate, poverty, high birth rate, joint and extended family, low level of education, patriarchy in the family etc. the domestic cooking is traditionally practiced by the female member of the family. This member can be wife, daughter or any other woman. For so long unquestionably women use to follow the traditions and socialization process teach them these norm or gender roles from very childhood. I have seen daughters or girls in the ages between 7-12 use to play with their peers which involves cooking with various tools of their own. During those childhood play stage if they are playing games which involve boys then they will just allow boys to go outside and find some stuffs from shops or stores so that they can cook with those bought items. I am just talking about childhood plays where nothing is real and yet we can sense how the idea that cooking is a female thing become intense and acceptable norms among the children. So, when they grow up then doing domestic cooking is something they use to enjoy and they don't feel psychologically tired of doing the same thing again and again. Even when they are really seek, without some exceptions, they will still complete their duty of

\footnotetext{
${ }^{9}$ Mahmud, A. (n.d.). Traditional Food Culture \&amp; Food Security in Bangladesh. Retrieved from

https://www.academia.edu/32445513/Traditional_Food_Culture_and_Food_S ecurity_in_Bangladesh
}

feeding the rest of the family. In fact, the nature of division of labor in the rural area is as such that men use to go outside the house in the early morning and they will stay in the agricultural land for the whole day. Sometimes, women use to cook for the family as well as deliver the food themselves to the men who are in the agricultural land during the lunch. There are numerous cases where if women fail to cook for anything to eat, let it be due to her sickness or unavailability of food items in the house for cooking, then are being severely abused by their male counterpart. Although, managing the food ingredients was a male duty and he actually liable for what happened. Men use to consider it a female thing to manage or borrow food from someone else or neighbors in order to cook something when their husband are poor enough to manage food on few occasions. If I talk about cooking outside the domestic settings then it's always a male thing in the rural Bangladesh. For example, on occasions like festivals or wedding ceremonies when hundreds of people are invited and the cooking needs to be done outside the house in an open place where people will be able to see who are cooking what then it's always the men. At the end of the occasions and during the occasions they will get appreciations from many people which are not available when you are cooking in a domestic setting. Besides, due to religious regulations women cannot be exposed in a public place doing cooking for so long. However, when it comes to collecting woods and natural materials as fuels that is again mostly up to the women of rural Bangladesh. Even, using axe to cut the trees and woods, which are also done by male people, are also being done by women in rural Bangladesh.

On the other hand, people in the urban area are characterized by man-woman both being employed, mostly nuclear family, highly educated, no agricultural orientation for earning, availability of maid. In urban setting if both male and female member are involved in jobs then they will either keep a female maid or women will manage her time to cook during nights or early mornings. However, in urban settings if any large number of people are invited for some occasions then families use to arrange that party using the help of a third party chefs and most of them are male. I have hardly seen male member of any household doing cooking on a regular basis in urban Bangladesh. They will do that for their amusement once in 3/4 months. Other than that, on the holidays or weekends they use to go to market to buy stuffs which are necessary for cooking. They just put their hand while their female mate is cooking in few activities which are like washing dishes, or chopping onions or something like that. However, in urban context, due to less access to play with the peers children do not learn their gender norms of cooking the same way rural children do. So, may be from the next generation we might see some changes in the habit or culture or norms.

\section{Social Inequality and Food Norms}

In the chapter 02 of "The Migrant's Table”, Ray has described the food norms of west Bengal. In doing so, he showed 
various aspects of food norms which represented the existence of social inequality and discrimination at a macro level. Using conflict perspective these issues can be addressed or at least an assumption of social structure can be made. We can see how the expenditure for food item consumption highly varied between rich and the poor. The access to resource and scarcity of access of resource is the core of conflict perspective's idea. Now only in the expenditure for food, but also for the percentage of the income being spend for food is also significantly dispersed. Poor family tend to spend almost most of their money for food and left behind less for other purposes of life. Besides, their intake of nutritious food also was in the lower stratum and this made them vulnerable to diseases and infant mortality. So, money as an indicator of someone's social position in the society affected the then people of lower class harshly and hence, they cannot come out of the vicious cycle of poverty.

Not only the income based inequality in 1970 west Bengal had created difference in culinary practice and norm, but few other factors within the society played crucial role in food norms. These norms included the age based differentiation among both rich and poor families, sex based unequal treatment; and variation in caste based norms also. Children used to have different dietary habit at various stages of their life. But they ended up following the culture of having less or more required nutrition depending on their respective family background. Even kids in poor family experienced discrimination on the basis of sex. So, we can see a double hammer on the girls in poor family. First for being in the poor family and second is being a girl. These practices were immensely influenced by traditional patriarchal social structure of west Bengal.

Women used to intake lesser than any other member of the society. However, the presence of iron at certain age of their life was a solid evidence that Ray mentioned in his writings. Female portion of the household tended to have leafy vegetables, courtesy the price of those food, which were among low status and less masculine food. In terms of milk consumption old aged women used to have it more. However, the cultural norms and religious rituals paved the way of this food related norms. Because, women, according to the culture of west Bengal and Hinduism needed to eat less, after their husbands dead or during their widowed days they could not have a certain type of food, and they had to be the last to eat. They were overlooked by the male dominated social structure of that time. Here we can see a domination of people based on their sexual orientation and thus a case of conflict sociological deal.

Children was enjoying a relatively different food access as described earlier. But in terms of age based inequality, children belong to a single age structure. Old aged people and adult people had a lag in their dietary intake. According to Ray,
"Older women appeared to bear the brunt of gender and age discrimination losing access to high-status items such as sliced bread, milk, fish, and meat. Hinduism, especially Vishnavism, provides convenient ideological justifications for older women's reduced access to most animal products and westernized items such as sliced bread viewing them as either polluting or producing excessive "heat" or sexual energy. Predictably, older women compensated by consuming more low status items, such as puffed rice and leafy vegetables" "I0 (Ray: 23).

Being a neighboring country and almost similar geographical nature Bangladesh resemblance very fairly with the food norms of west Bengal. I must admit the fact that ecological status decided the type of food for both the locality which is just divided by political boundary. However, religion also might have had few impact but not to a great extent. The core of the meal is always the rice, wheat and roti. But the fringe also featured by vegetables and curries as alike. Only difference can be found in the inclusion of beef item in the food cart. The distinctive use of item like turmeric in the overall cuisine in west Bengal made the taste identifiable from other area's food taste. I was wondering if only the beef part and the presentation of food on the table part is excluded it would have seemed identical with Bangladesh's food uniqueness. With these slightest of differences in food norms and geological similarity, the explanation of Ray can easily be used to understand the root of Bangladeshi food norms and main food items.

\section{CONCLUSION}

Migration places a person's sense of being and identity in a state of flux; they have to (re)build their identities and relationships as they are pushed in multiple directions and subjected to a range of stresses and changes in their daily lives. As will be evident, food has been shown to play a significant role in ' anchoring ' a migrant across a number of ethnographic contexts, while also enabling new subjectivities and orientations to be established. Ray explains how migrants build culinary identities and establish gustatory boundaries in relation to ' other'.

\footnotetext{
${ }^{10}$ Ray, Krishnendu. (2004). The Migrant's Table: Meals \& Memories in Bengali-American Households. Temple University Press
} 